\title{
STUDI PENGETAHUAN, SIKAP DAN TINDAKAN PEDAGANG TENTANG PENGELOLAAN SAMPAH DI PASAR UMUM UBUD KECAMATAN UBUD KABUPATEN GIANYAR TAHUN 2017
}

\author{
Dewa Ayu Oka Putri Andriani ${ }^{1}$ D.A.A.Posmaningsih²
}

\begin{abstract}
Ubud Public Market is visited by many foreign and local tourists. The increase of tourists to Ubud caused a negative impact from the development of tourism is the environment because the amount of waste generated in every place. The level of knowledge and awareness of traders in terms of waste management is still very less, seen from the general aspects of waste management is the stage of collection, transportation and final disposal. The purpose of this research is to know the knowledge, attitude and actions of trader's about waste management at Ubud Public Market Ubud Subdistrict Gianyar Regency 2017. This research type is descriptive observasional. Samples in this research are 100 traders selling at Ubud Public Market Ubud Subdistrict Gianyar Regency. The data collected in this research are primary and secondary data. Data collection was done by using questionnaires to assess the level of knowledge, attitude and action of traders and observation sheet used to observe directly the waste management in Ubud Public Market Ubud Subdistrict Gianyar Regency. The data has been collected and then processed and presented in the form of tables or graphs. The result of this research is a traders with good knowledge of 49 people (49\%), traders who have good attitude 51 people (51\%), traders who have medium action 76 people (76\%).
\end{abstract}

Keywords: Knowledge, Attitude, Action and Waste Management

\section{Pendahuluan}

Pasar Umum Ubud merupakan pasar umum yang juga merupakan pasar seni yang banyak didatangi oleh wisatawan mancanegara maupun lokal. Selain menyediakan kebutuhan pokok masyarakat, terdapat juga suvenir khas Bali yang disediakan untuk wisatawan. Sehingga tempat ini menjadi salah satu tujuan utama wisata Bali bagi wisatawan domestik maupun mancanegara. Produk segar seperti buah-buahan, sayuran, unggas dan makanan ringan lokal dapat dibeli dari pasar basah terletak di ruang bawah tanah gedung (1).

Peningkatan jumlah wisatawan yang datang ke Ubud memiliki dampak positif dan negatif. Dampak positif dari perkembangan pariwisata adalah mendatangkan pendapatan tetap bagi masyarakat, sehingga perkembangan ekonomi dan pembangunan kian meningkat. Meskipun memiliki dampak positif 
peningkatan wisatawan ke Ubud juga mendatangkan dampak negatif yaitu rusaknya lingkungan karena banyaknya sampah yang dihasilkan di setiap tempat yang banyak terdapat aktivitas seperti pasar (2).

Upaya-upaya

dalam pengelolaan sampah di Pasar Umum Ubud, Kecamatan Ubud, Kabupaten Gianyar belum berjalan sesuai dengan sistem pengelolaan sampah yang sudah ada di Kabupaten Gianyar (3). Upaya- upaya yang dilakukan Pemerintah Kabupaten Gianyar tidak didukung penuh oleh peran pedagang. Kurangnya kesadaran masyarakat untuk ikut dalam pengelolaan sampah menjadi hambatan terbesar. Padahal jika sampah dikelola bersama-sama dengan baik akan menciptakan lingkungan yang bersih dan sehat (4).

Salah satu gambaran buruk sistem pengelolaan sampah yang terjadi di Pasar Umum Ubud tercermin dari masih banyaknya timbulan dan tumpukan sampah pada daerah sekitar tempat penampungan sementara (TPS), karena kurangnya armada sampah dari TPS ke TPA. Hal tersebut juga diakibatkan oleh luasnya daerah yang harus dilayani, terbatasnya sarana dan prasarana, dana dan sumber daya manusia yang dimiliki oleh pengelola Pasar Umum Ubud, sehingga terjadi ketidakseimbangan antara pelayanan dengan volume timbulan sampah.

Berdasarkan

survei pendahuluan dengan menggunakan 30 pedagang sebagai responden, $77 \%$ pedagang di Pasar Umum Ubud tidak memiliki tempat penampungan sampah yang memenuhi syarat seperti masih menggunakan keranjang dari anyaman bambu. Pedagang yang tidak mempunyai kotak sampah mereka akan membuang sampah di sekitar tempat pedagang, sehingga akan merusak estetika pasar sebagai tujuan wisata. Dalam mengelola sampah 67\% pedagang tidak mengetahui jenis sampah dan $60 \%$ pedagang mengatakan bahwa sampah tidak perlu dipilah, hanya $40 \%$ pedagang yang mengatakan sampah perlu dipilah tetapi masih saja terlihat pada tempat sampahnya menggabungkan sampah organik dan anorganik. Tujuan dari penelitian ini adalah untuk mengetahui pengetahuan, sikap dan tindakan pedagang tentang pengelolaan sampah di Pasar Umum 
Ubud Kecamatan Ubud Kabupaten Gianyar Tahun 2017.

\section{Metode Penelitian}

Jenis penelitian yang digunakan adalah deskriptif observasional dengan rancangan penelitian cross sectional. Tempat penelitian adalah di Pasar Umum Ubud Jalan Raya Ubud No.35 Kecamatan Ubud, Kabupaten Gianyar dengan waktu penelitian bulan Mei sampai Juni 2017. Populasi pada penelitian ini dalah 716 pedagang, dan sampel pada penelitian ini adalah 100 pedagang yang berjualan di Pasar Umum Ubud Kecamatan Ubud Kabupaten Gianyar. Pengumpulan data dilakukan dengan menggunakan lembar kuesioner untuk menilai tingkat pengetahuan, sikap dan tindakan pedagang yang berjualan di Pasar Umum Ubud Kecamatan Ubud Kabupaten Gianyar dan lembar observasi digunakan untuk mengamati secara langsung pengelolaan sampah di Pasar Umum Ubud Kecamatan Ubud Kabupaten Gianyar. Data yang sudah dikumpulkan kemudian diolah dan disajikan dalam bentuk tabel atau grafik.

\section{Hasil Penelitian}

1. Karakteristik responden

Dari 100 responden diperoleh hasil jenis kelamin yang mendominasi responden adalah wanita yaitu sebanyak 71 orang (71\%). Umur yang mendominasi responden yaitu 35 tahun sebanyak 55 orang $(55 \%)$. Pendidikan terakhir responden yang paling banyak yaitu tamat SMA sebanyak 52 orang $(52 \%)$.

2. Data pengetahuan responden Tabel 1

Distribusi Responden Berdasarkan

Pengetahuan dalam Pengelolaan

Sampah di Pasar Umum Ubud

Kecamatan Ubud Kabupaten Gianyar Tahun 2017

\section{No Pengetahuan Frekuensi}

Persentase

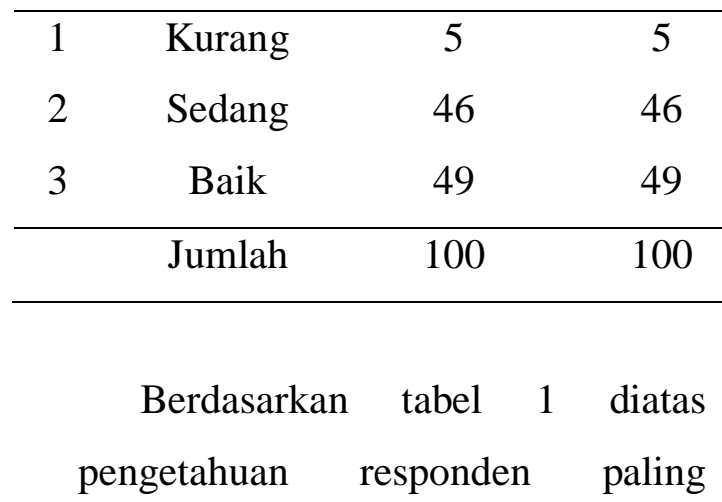


banyak dalam kategori baik yaitu $49 \%$.

3. Data sikap responden

Tabel 2

Distribusi Responden Berdasarkan

Sikap dalam Pengelolaan Sampah di

Pasar Umum Ubud Kecamatan Ubud

Kabupaten Gianyar Tahun 2017

\begin{tabular}{cccc}
\hline No & Sikap & Frekuensi & $\begin{array}{c}\text { Persentase } \\
(\%)\end{array}$ \\
\hline 1 & Kurang & 14 & 14 \\
2 & Sedang & 35 & 35 \\
3 & Baik & 51 & 51 \\
\hline & Jumlah & 100 & 100 \\
\hline
\end{tabular}

Berdasarkan tabel 2 diatas sikap responden paling banyak dalam kategori baik sebesar $51 \%$.
4. Data tindakan responden

Tabel 3

Distribusi Responden Berdasarkan

Tindakan dalam Pengelolaan

Sampah di Pasar Umum Ubud

Kecamatan Ubud Kabupaten Gianyar

Tahun 2017

No Tindakan Frekuensi

Persentase

\begin{tabular}{|c|c|c|c|}
\hline 1 & Kurang & 7 & 7 \\
\hline 2 & Sedang & 76 & 76 \\
\hline 3 & Baik & 17 & 17 \\
\hline & Jumlah & 100 & 100 \\
\hline
\end{tabular}

tindakan responden paling banyak dalam kategori sedang sebesar $76 \%$.

5. Data observasi pengelolaan sampah di Pasar Umum Ubud Pengelolaan sampah di Pasar Umum Ubud dalam kategori kurang berdasarkan observasi lapangan di Pasar Umum Ubud dapat diketahui bahwa dari 16 indikator yang dilihat dilapangan hanya $31,25 \%$ indikator yang memenuhi syarat yaitu setiap kios/los tersedia tempat sampah, tersedianya TPS di pasar, tersedia petugas pengangkut sampah (petugas kebersihan) dari kios/ los ke TPS, tersedianya peralatan 
pembersih sampah, tersedianya alat pengangkut sampah.

\section{Pembahasan}

\section{Pengetahuan responden}

Berdasarkan hasil penelitian menunjukkan sebagian besar pengetahuan responden mengenai pengelolaan sampah dalam kategori baik yaitu sebanyak 49 orang (49\%) dan pengetahuan responden dalam kategori sedang sebanyak 46 orang (46\%). Pengetahuan responden dalam kategori kurang hanya 5 orang (5\%). Tingkat pengetahuan responden sangat dipengaruhi oleh pendidikan terakhir dari masingmasing responden. Tingkat pendidikan responden di Pasar Umum Ubud secara umum tamatan SMA dan SMP. Semakin tinggi tingkat pendidikan maka tingkat pengetahuan pedagang juga akan semakin baik pula dalam hal pengelolaan sampah (5).

Tingkatan

pengetahuan

responden dalam mengelola sampah pasar dengan persentase terbesar pada kategori baik. Namun, masih terdapat beberapa responden yang tingkat pengetahuannya berada pada katagori sedang dan kurang. Dapat dijelaskan bahwa pengetahuannya hanya mengetahui dan memahami, belum mampu mengaplikasikan, menganalisis, mensintesis ataupun mengevaluasi (6).

Pengetahuan pedagang mengenai pengelolaan sampah pasar yang belum baik akan mempengaruhi hidup bersih dan sehat masyarakat itu sendiri. Hal ini sesuai dengan pendapat Green yang dikutip Notoatmodjo (2003) yang menyebutkan bahwa pengetahuan merupakan salah satu faktor yang mempermudah terjadinya perilaku seseorang. Dengan demikian peningkatan pengetahuan pedagang tentang pengelolaan sampah pasar dalam kehidupan sehari-hari penting dalam upaya meningkatkan perilaku hidup bersih dan sehat. Hasil penelitian (7) menunjukkan ada hubungan pengetahuan terhadap pengelolaan sampah dengan memberikan kontribusi sebesar 20,6 $\%$ dalam perubahan prilaku masyarakat. Pihak Puskesmas seharusnya memberikan penyuluhan mengenai dampak yang ditimbulkan oleh sampah terhadap kesehatan agar pedagang dapat mengetahui dan memahami cara pengelolaan sampah 
yang baik demi terwujudnya derajat kesehatan.

2. Sikap responden

Berdasarkan hasil penelitian menunjukkan secara umum responden memiliki sikap dalam kategori baik yaitu sebanyak 51 orang (51\%), dalam kategori sedang sebanyak 35 orang $(35 \%)$ dan kategori kurang sebanyak 14 orang (14\%). Sikap adalah suatu respon tertutup seseorang terhadap stimulus atau objek tertentu, yang sudah melibatkan faktor pendapat dan emosi yang bersangkutan. Sikap adalah merupakan reaksi atau respon seseorang yang masih tertutup terhadap suatu stimulus atau objek (6).

Sikap yang kurang akan mempengaruhi tindakan yang kurang juga. Menurut Ajzen yang dikutip oleh (8), sikap terbentuk dari adanya informasi secara formal maupun informal yang diperoleh oleh setiap individu. Berarti sikap sejalan dengan pengetahuan, apabila pengetahuan seseorang baik maka sikap juga baik. Berdasarkan hasil penelitian dapat dijelaskan bahwa sikap pedagang yang kategori sedang dapat dikatakan masih pada tingkatan menghargai namun belum dapat bertanggungjawab sehingga memungkinkan masyarakat melakukan tindakan yang kurang. Sikap pedagang yang baik belum tentu menghasilkan tindakan yang baik pula. Dalam penerapan sikap terkadang tidak sejalan dengan tindakan, hal ini dikarenakan untuk mewujudkan sikap menjadi suatu tindakan nyata perlu faktor pendukung diantaranya fasilitas ataupun dukungan dari pihak lain (9). Hal ini sesuai dengan menyatakan bahwa sikap berpengaruh terhadap perubahan prilaku masyarakat dalam pengelolaan sampah sebesar 24,9\%, sedangkan fasilitas memberikan kontribusi sebesar 36,2\%.

3. Tindakan responden

Berdasarkan hasil penelitian menunjukkan secara umum responden memiliki tindakan dalam kategori sedang yaitu sebanyak 76 orang $(76 \%)$ dan tindakan responden dalam kategori baik sebanyak 17 orang $(17 \%)$. Tindakan responden dalam kategori kurang hanya 7 orang (7\%).

Adanya hubungan yang erat antara sikap dan tindakan didukung 
oleh pengetahuan. Tindakan yang positif sangat dipengaruhi oleh pengetahuan dan sikap seseorang dalam menerima perubahan dan memerlukan factor pendukung. Suatu sikap belum terwujud dalam suatu tindakan (overt behavioral). Untuk terwujudnya sikap agar menjadi suatu perbuatan nyata diperlukan faktor pendukung atau suatu kondisi yang memungkinkan yang berupa fasilitas. Di samping itu ada faktor dukungan (support) dari pihak lain di dalam praktek atau tindakan (6).

Dalam hal ini tindakan responden mengenai pengelolaan sampah di Pasar Umum Ubud dalam kategori sedang. Sikap pedagang yang hanya menerima saran dan belum mampu bertanggung jawab dalam pengelolaan sampah di pasar. Faktor pendukung seperti pendidikan dan sarana pengelolaan sampah merupakan faktor pendukung yang memungkinkan responden tidak mau melakukan tindakan baik untuk mengelola sampah pasar di Pasar Umum Ubud. Untuk itu, pengelola pasar dan petugas kebersihan perlu memberikan informasi mengenai prosedur pengelolaan sampah yang baik kepada pedagang dan menyediakan fasilitas yang cukup untuk memberikan contoh kepada pedagang untuk dapat melakukan pengelolaan sampah yang baik di Pasar Umum Ubud. Dengan tersedianya fasilitas yang memadai di Pasar Umum Ubud maka sampah tidak akan berserakan lagi dan dapat tertampung sesuai jumlah sampah yang dihasilkan pasar.

4. Pengelolaan sampah di Pasar Umum Ubud

Pengelolaan sampah di Pasar Umum Ubud dalam kategori kurang berdasarkan observasi lapangan di Pasar Umum Ubud dapat diketahui bahwa dari 16 indikator yang dilihat dilapangan hanya 31,25\% indikator yang memenuhi syarat yaitu setiap kios/los tersedia tempat sampah, tersedianya TPS di pasar, tersedia petugas pengangkut sampah (petugas kebersihan) dari kios/ los ke TPS, tersedianya peralatan pembersih sampah, tersedianya alat pengangkut sampah.

Berdasarkan hasil observasi lapangan di Pasar Umum Ubud perlu adanya kesadaran antara pedagang, pengelola pasar dan petugas kebersihan untuk dapat menerapkan pemilahan sampah antara sampah 
organik dengan sampah anorganik. Pedagang juga harus memiliki tempat sampah yang memenuhi syarat kesehatan agar sampah yang dibuang tidak menjadi tempat perkembangbiakan vektor penyakit. Pengelola pasar harus ikut serta dalam peningkatan kebersihan pasar dengan upaya penyediaan fasilitas pengelolaan sampah yang baik dan memadai.

Pasar merupakan tempat umum yang banyak dikunjungi oleh masyarakat, oleh sebab itu pasar merupakan tempat menyebarnya segala penyakit terutama penyakit yang medianya makanan, minuman, udara dan air. Dengan demikian sanitasi tempat-tempat umum harus memenuhi persyaratan kesehatan dalam arti melindungi, memelihara, dan meningkatkan derajat kesehatan masyarakat (10).

Dalam pengelolaan sampah, hal yang perlu mendapat perhatian adalah proses pemilahan sampah. Hal ini bisa diawali dengan membedakan tempat sampah berdasarkan jenis-jenis sampah harian. Identifikasi jenis sampah yang dihasilkan akan sangat berpengaruh terhadap proses pengelolaan selanjutnya (11)

Salah satu tindakan yang tepat dalam pengolahan sampah pasar ini adalah dengan menjadikannya kompos. Karena lebih dari $60 \%$ sampah yang dihasilkan di pasar ini adalah sampah organik. Menurut percobaan yang dilakukan compos centre USU dalam satu kali pengolahan sampah dapat menghasilkan kompos sebesar 30-40 persen, dari berat sampah di awal. Sehingga jika semakin banyak sampah organik pada suatu pasar,maka potensi kompos yang dihasilkan akan semakin banyak pula. Disamping pengolahan sampah organik, dapat pula dilakukan pengolahan sampah anorganik, dalam hal ini dapat dilakukan dalam bentuk daur ulang, maupun pemanfaatan kembali bahan-bahan yang masih layak untuk dipakai.(12)

Hasil penelitian tentang pengelolaan Sampah organik pasar Sampangan Baru sudah diolah menjadi pupuk kompos dan diperjualbelikan. Pengolahan sampah dengan baik bisa dikemas dan dijual itu akan memberikan penghasilan tambahan pada Pengelola Pasar. (13) 
Proses pengelolaan sampah di pasar sangat tergantung pada kondisi dan ketersediaan alat-alat penunjang, namun kebutuhan akan alat penunjang. Dukungan Pemerintah untuk menyediakan fasilitas pengelolaan sampah sangat dibutuhkan. Pemberian sanksi tegas yang diberikan kepada masyarakat yang membuang sampah di TPS juga harus dilaksanakan sehingga memberikan kesadaran kepada masyarakat untuk mengelola sampahnya dengan baik.(14) Berdasarkan teori manajemen pada salah satu proses manajemen yaitu pengawasan atau controlling, yang seharusnya manajer atau dalam hal ini koordinator kebersihan dapat memastikan dapat memastikan pekerjaan telah sesuai dengan yang direncanakan atau sesuai dengan tujuan..(14)

\section{Simpulan}

Adapun simpulan dari penelitian ini antara lain:

1. Pengetahuan responden mengenai pengelolaan sampah dalam kategori baik yaitu sebanyak 49 orang (49\%), dalam kategori sedang sebanyak 46 orang $(46 \%)$ dan kategori kurang hanya 5 orang $(5 \%)$.

2. Sikap responden dalam kategori baik yaitu sebanyak 51 orang (51\%), dalam kategori sedang sebanyak 35 orang (35\%) dan kategori kurang sebanyak 14 orang (14\%).

3. Tindakan responden dalam kategori sedang yaitu sebanyak 76 orang $(76 \%)$, dalam kategori baik sebanyak 17 orang (17\%), dan kategori kurang hanya 7 orang $(7 \%)$.

4. Pengelolaan sampah di Pasar Umum Ubud dalam kategori kurang berdasarkan observasi lapangan di Pasar Umum Ubud dapat diketahui bahwa dari 16 indikator yang dilihat dilapangan hanya $31,25 \%$ indikator yang memenuhi syarat.

\section{Saran}

1. Kepada pihak pengelola Pasar Umum Ubud dan Puskesmas agar melakukan penyuluhan mengenai dampak sampah bagi kesehatan, untuk meningkatkan pengetahuan pedagang mengenai pentingnya kesehatan, sehingga pedagang akan merubah sikap dan 
tindakannya untuk memenuhi kesehatannya dan kebersihan lingkungan sekitar Pasar Umum Ubud.

2. Kepada pengelola Pasar Umum Ubud dan Dinas Kebersihan dan Pertamanan Kabupaten Gianyar agar senantiasa memberikan informasi mengenai prosedur pengelolaan sampah yang baik, dan bersedia untuk memfasilitasi sarana dan prasarana untuk pengelolaan sampah yang baik di Pasar Umum Ubud menerapkan manajemen pengawasan pengelolaan sampah dan mengupauakan mengolah sampah menjadi kompos.

3. Kepada pedagang di Pasar Umum Ubud agar dapat menyediakan wadah penyimpanan sampah yang sesuai dengan syarat kesehatan serta meningkatkan pengetahuan, sikap dan tindakan dalam mengelola sampah.

4. Diharapkan kepada peneliti selanjutnya untuk membuat kuesioner yang tidak menimbulkan perilaku social desirability bias dari responden.

\section{Daftar Pustaka}

1. Wikipedia. Pasar Seni Ubud. In: Wikipedia. 2017.

2. Ardana. Pengaruh

Perkembangan Pariwisata

Terhadap Struktur

Perekonomian dan

Kesejahteraan Masyarakat

Bali. 2013;

3. Raka. Evaluasi Sistem

Pengelolaan Sampah

Kabupaten Gianyar. ITS

Surabaya; 2007.

4. Netty. Gianyar Menuju

Terwujudnya Permukiman

Yang Sehat, Bersih, Bebas

Sampah dan Air Limbah.

2014;

5. Riyanto dan Budiman.

Pengetahuan dan Sikap Dalam

Penelitian Kesehatan. Jakarta:

Salemba Medika; 2013.

6. Notoatmodjo S. Ilmu

Kesehatan Masyarakat.

Kedua. Jakarta: PT. Rineka

Cipta; 2003.

7. Posmaningsih DAA. Faktor -

Faktor Yang Mempengaruhi

Partisipasi Masyarakat Dalam

Pengelolaan Sampah Padat Di

Denpasar Timur. Jurna Skala

Husada (The Journal of 
Health. 2016;3(1). Available

from:

http://ejournal.poltekkes-

denpasar.ac.id/index.php/JSH/

article/view/79/36

8. Azwar A. Pengantar Ilmu

Kesehatan Lingkungan.

Kelima. Jakarta: PT. Mutiara

Sumber Widya; 1990.

9. Siahaan T. Analisa Sistem

Pengelolaan Sampah dan

Perilaku Pedagang di Pasar

Horas Kota Pematangsiantar

Tahun 2013. Sumatera Utara;

2013.

10. Mukono. Prinsip Dasar

Kesehatan Lingkungan.

Surabaya: Airlangga

University Press; 2006.

11. Fadhilah A, Sugianto H, Hadi

K, Firmandhani SW, Woro T,

Pandelaki EE. Kajian

Pengelolaan Sampah Kampus.

Modul. 2011;11(2):62-71.

12. Ramadhani A, Perwira A,

Tarigan M, Sipil DT, Utara

US, Perpustakaan J, et al.

Studi Pengelolaan Sampah

Pasar Kota Medan. J Tek Sipil

USU. 2014;(1):1-12.

13. Dyah Rini Indriyanti, Eva

Banowati M. Pengolahan
Limbah Organik Sampah

Pasar Menjadi Kompos.

ABDIMAS. 2015;19(1):43-8.

14. Widodo T. Studi Tentang

Peranan Unit Pasar Dalam

Pengelolaan Sampah Di Pasar

Merdeka Kota Samarinda.

Adm Negara. 2013;1(112):1-

7. 